\title{
Large Foreign Body in the Nasal Cavity, Maxillary Sinus and Infratemporal Fossa-Atypical Presentation
}

\author{
Subrat Kumar Behera ${ }^{1}$, Niranjan Mishra ${ }^{2}$, Sharath Govindappa ${ }^{1}$ \\ ${ }^{1}$ Department of ENT, S.C.B. Medical College, Cuttack, India \\ ${ }^{2}$ Department of OMFS, S.C.B. Medical College, Cuttack, India \\ Email: sharathg2006@gmail.com
}

Received 5 September 2014; revised 4 October 2014; accepted 3 November 2014

Copyright (C) 2014 by authors and Scientific Research Publishing Inc.

This work is licensed under the Creative Commons Attribution International License (CC BY).

http://creativecommons.org/licenses/by/4.0/

c) (i) Open Access

\begin{abstract}
A 59-year-old male presented with complaints of trismus and discharge of altered blood from nose for 1 year. Patient had a history of facial trauma one year back. Nasal endoscopy and CT scan revealed a foreign body lodged in posterior half of both nasal cavity, left maxillary sinus and left infratemporal fossa penetrating the walls of maxillary sinus and nasal septum. Foreign body was removed by infratemporal fossa approach. This case has a rare location of a forgotten foreign body with atypical presentation.
\end{abstract}

\section{Keywords}

Foreign Body, Nose and Paranasal Sinuses, Infratemporal Fossa, Trismus

\section{Introduction}

In day-to-day practice, patients frequently present with lodgment of foreign bodies in the nasal cavities. Foreign bodies in the paranasal sinuses (PNS) are not common. Sharma et al. [1] reported a case of wooden foreign body in the periorbita of right eye, extending into the right sphenoid and ethmoidal sinuses. Mathews et al. [2] reported the base of a wristwatch in the left maxillary sinus and pterygopalatine fossa. Dutta et al. [3] reported a splinter (part of a bullet) in the right maxillary sinus. In this case, the patient had a $8 \mathrm{~cm}$ wooden foreign body lodged in posterior half of both nasal cavities, left maxillary sinus and left infra temporal fossa having to pierce the walls of maxillary sinus and nasal septum. The reason behind reporting this case is rarity of foreign body location and its atypical presentation. 


\section{Case Report}

A 59-year-old male presented with complaints of trismus since 1 year and altered blood discharge from both nostrils also from 1 year (Figure 1). Patient had history of fall from tree and a penetrating injury to the left temporal area, which was sutured and the patient had speedy recovery.

On general physical examination, the patient was apparently healthy. The medical history was not significant and routine haematological investigations were within normal limits. A clinical intraoral examination revealed decreased mouth opening with normal healthy oral mucosa. On examination of nose, anterior rhinoscopy was normal. Nasal endoscopy revealed a blackish brown foreign body in posterior half of both nasal cavities (Figure 2).

Patient underwent CT scan (Figure 3, Figure 4) it revealed a non-metallic foreign body in the posterior part of nasal cavity, left maxillary sinus and left infratemporal fossa, piercing the walls of maxillary sinus nasal septum abutting near the posterior end of inferior turbinates.

Under general anaesthesia the foreign body was removed by infratemporal fossa approach. Using Al-Kayat Bramley's incision and zygomatic arch osteotomy foreign body was accessed and removed in single piece (Figure 5, Figure 6). Postoperative intravenous antibiotics and anti-inflamatory drugs were given.

Patient recovered well with 4 finger mouth opening at 2 weeks.

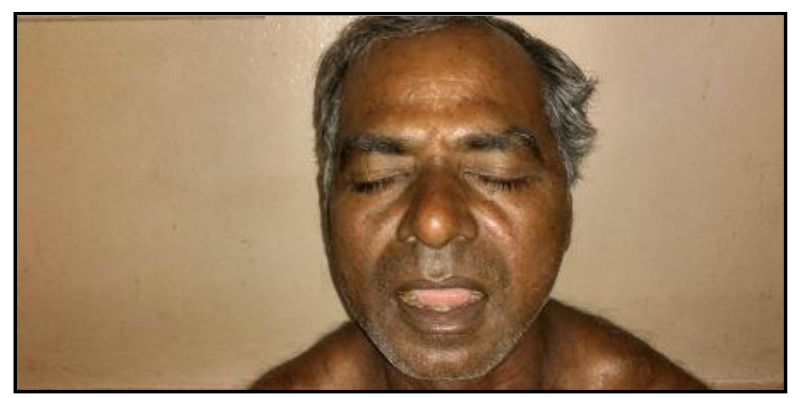

Figure 1. Trismus.

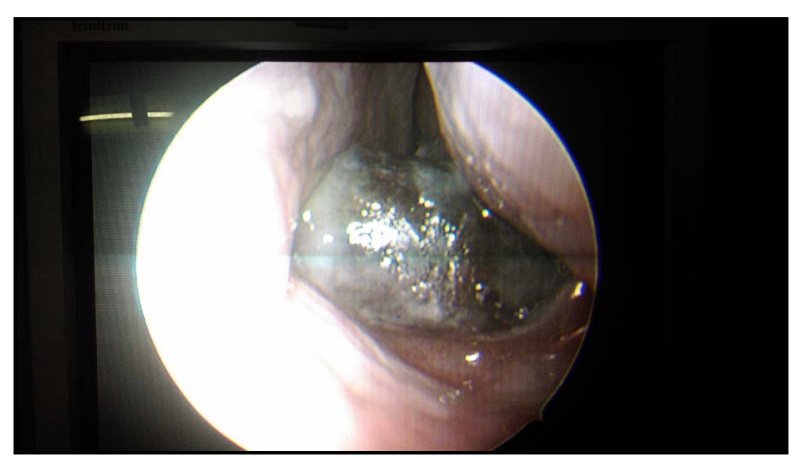

Figure 2. Nasal endoscopy showing foreign body.

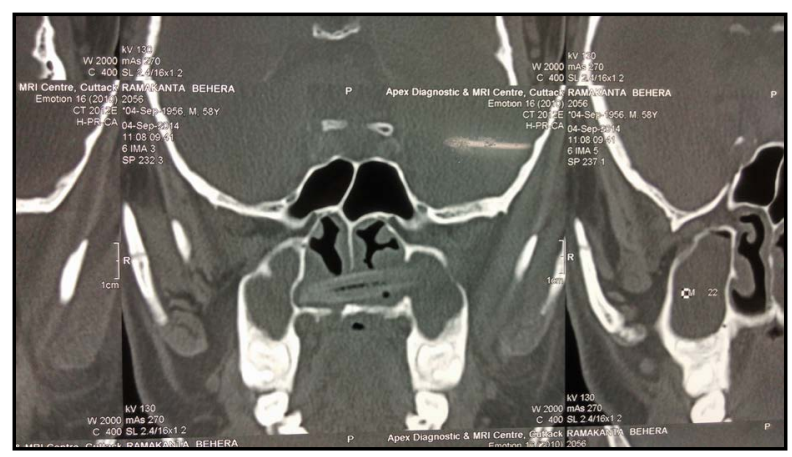

Figure 3. CT scan showing foreign body in nasal cavity. 


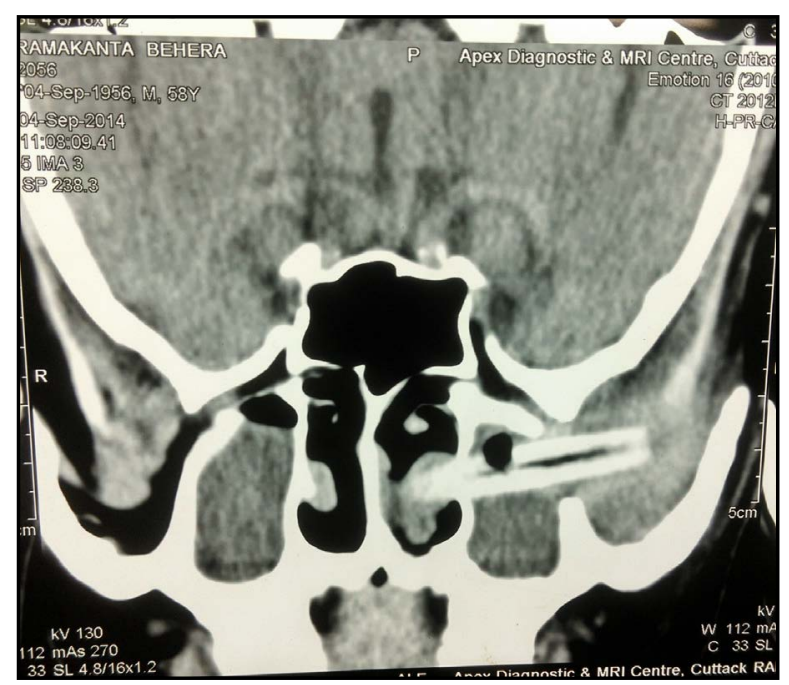

Figure 4. CT scan showing foreign body in maxillary sinus and infratemporal fossa.

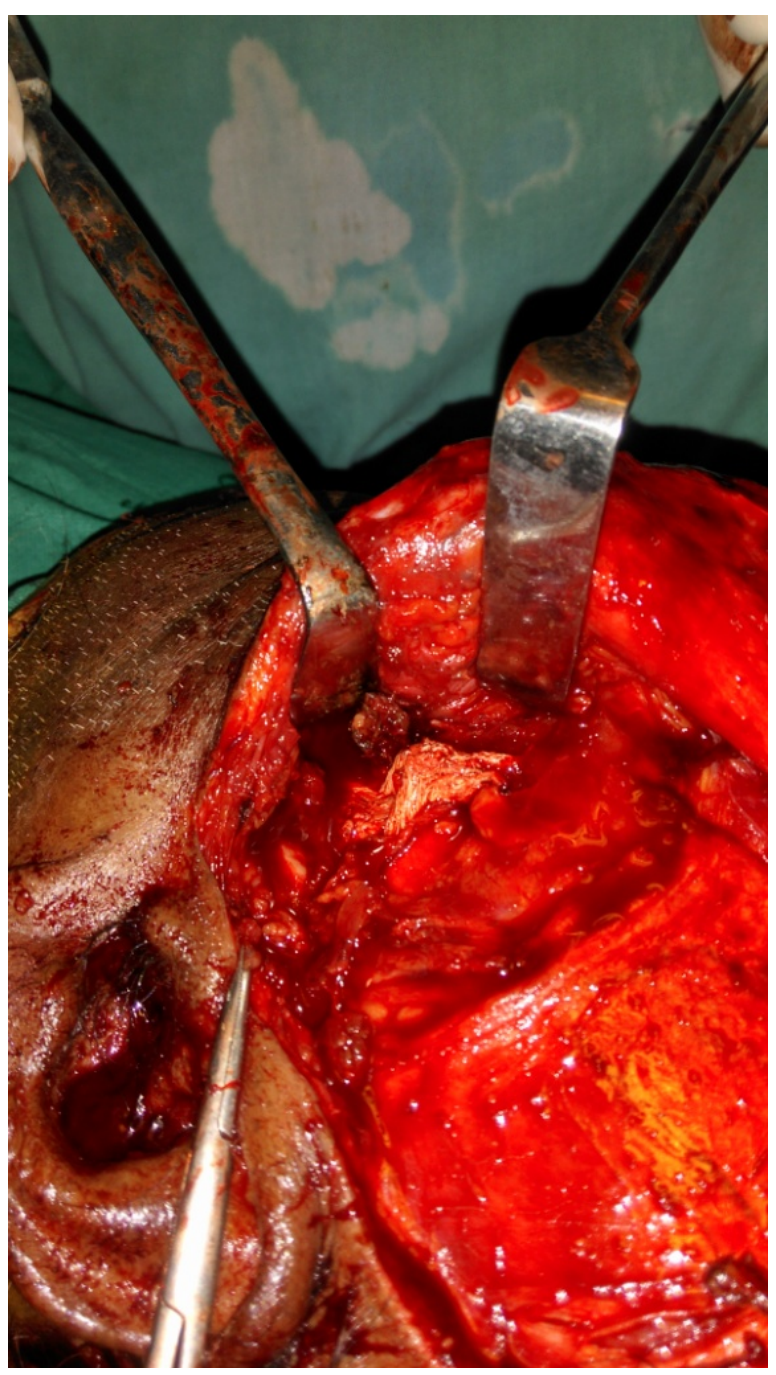

Figure 5. Intra operative picture of foreign body. 


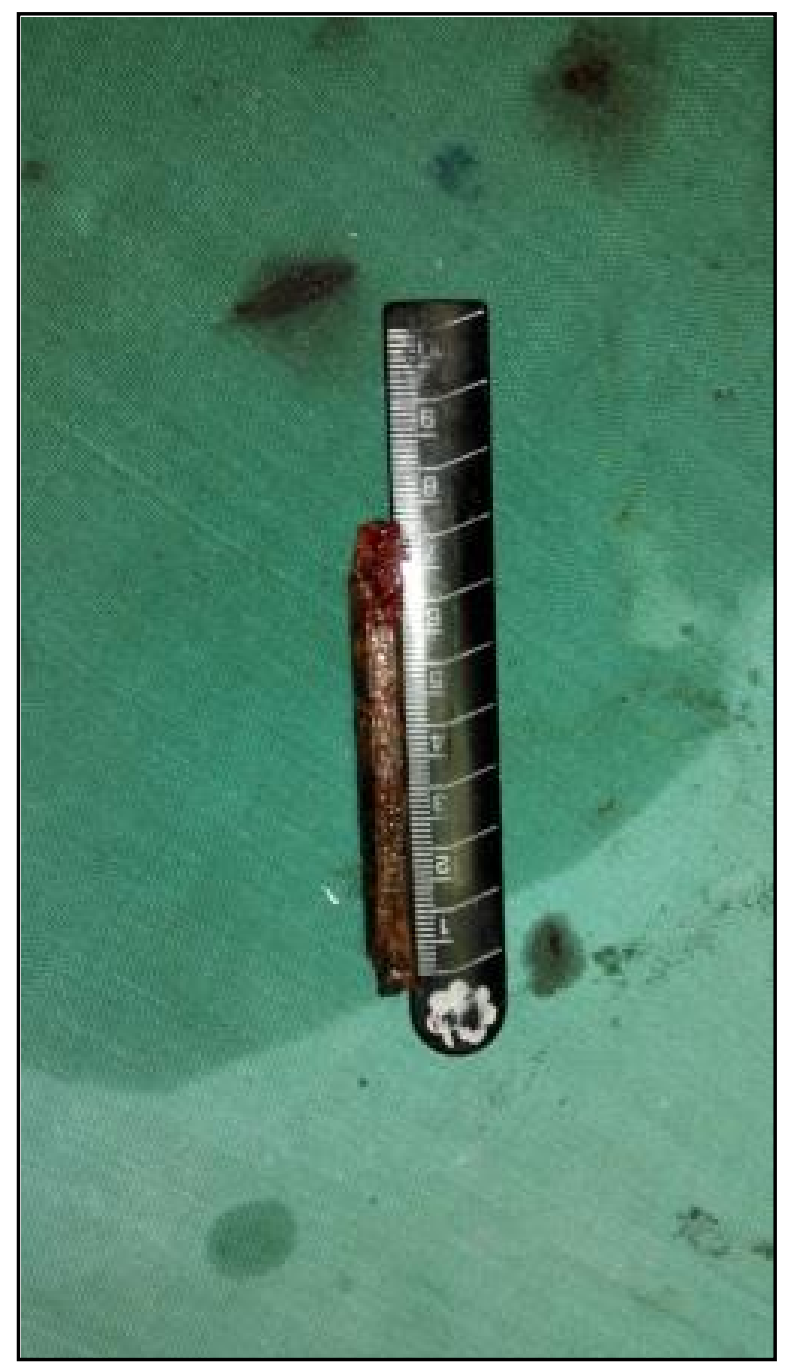

Figure $6.8 \mathrm{~cm}$ foreign body removed in single piece.

\section{Discussion}

Foreign bodies in the PNS are not common. They are usually traumatic and in some cases iatrogenic. In most of the case reports pertaining to the foreign body infratemporal fossa the foreign body had found its way into the region following trauma and the main clinical symptom being trismus [4] [5]. Keeping in view the other important organs like eye and brain in the immediate vicinity of the space and its potential communicating portals with these organs via the anatomical foraminas, the foreign body in such a location with its potential to cause inflammatory reaction and tendency to migrate is always a potential threat for causing serious complications like proptosis with threat to vision and various intracranial complication [6]. Here we have a foreign body lodged in nasal cavity left maxillary sinus and left infratemporal fossa.

Foreign bodies in the PNS include splinters [1], gun pellets, woods [7], etc. Radio-opaque foreign bodies can easily be detected by X-ray of PNS anteroposterior and lateral views. X-ray of PNS anteroposterior view is better than occipeto-mental view as it helps better in assessing the actual position of the foreign bodies. CT scan and magnetic resonance imaging (MRI) may be necessary in some cases especially radio opaque foreign bodies.

Foreign bodies in the nose and PNS should be removed as early as possible. A retained foreign body can lead to sinusitis, cutaneous fistula and foreign body granuloma formation.

Caldwell-Luc approach is the usual procedure for removal of foreign bodies from maxillary sinuses. Endoscopic approach has the advantage of better visualization and illumination. In this case the foreign body was big measuring $8 \mathrm{~cm}$ impacted in the nasal cavity maxillary sinus and infra temporal fossa. In order to remove the 
foreign body in one piece and prevent detainment of parts of foreign body an infratemporal fossa approach was used, which was also the route of entry of the foreign body.

\section{Conclusion}

A variety of foreign bodies ranging from wooden objects to bullets can be found in the nose and PNS. They can vary in size, shape, and location. Sometimes they can be found accidentally. Foreign bodies should be considered in the differential diagnosis of trismus, especially in patients with recent past history of trauma in the region and the possibility of missing some parts of foreign body during the initial emergency salvage procedures for such cases of trauma. The route and method of removal is decided based on the size, shape, and location of the foreign body. Use of nasal endoscopes can be very helpful for this purpose.

\section{References}

[1] Sharma, R., Minhass, R. and Mohindroo, M. (2008) An Unusual Foreign Body in the Paranasal Sinuses. Indian Journal of Otolaryngology and Head Neck Surgery, 60, 88-90. http://dx.doi.org/10.1007/s12070-008-0028-7

[2] Mathews, A., Nair, A., Tandon, S. and D’Souza, O. (2010) Penetrating Foreign Body in the Maxillary Sinus and Pterygopalatine Fossa: Report of a Rare Case. Internet Journal of Head \& Neck Surgery, 4, 9.

[3] Dutta, A., Awasthi, S.K. and Kaul, A. (2006) A Bullet in the Maxillary Sinus. Indian Journal of Otolaryngology and Head Neck Surgery, 58, 307-309.

[4] Purohit, J.P., Kumar, G., Singh, P.N. and Ganesh, K. (1996) An Unusual Foreign Body in Infratemporal Fossa. Indian Journal of Otolaryngology and Head Neck Surgery, 48, 323-324.

[5] Thakur, J.S., Chauhan, C.G.S., Diwana, V.K. and Chauhan, D.C. (2007) Trismus: An Unusual Presentation Following Road Accident. Indian Journal of Plastic Surgery, 40, 202-204. http://dx.doi.org/10.4103/0970-0358.37769

[6] Grant, C.A. and Rubin, P.A.D. (2000) An Infratemporal Fossa Foreign Body Presents as an Infraorbital Mass. Archives of Ophthalmology, 118, 993-995.

[7] Lineback, M. (1955) Wooden Foreign Bodies in the Paranasalsinuses. Laryngoscope, 65, 270-275. http://dx.doi.org/10.1288/00005537-195504000-00005 
Scientific Research Publishing (SCIRP) is one of the largest Open Access journal publishers. It is currently publishing more than 200 open access, online, peer-reviewed journals covering a wide range of academic disciplines. SCIRP serves the worldwide academic communities and contributes to the progress and application of science with its publication.

Other selected journals from SCIRP are listed as below. Submit your manuscript to us via either submit@scirp.org or Online Submission Portal.
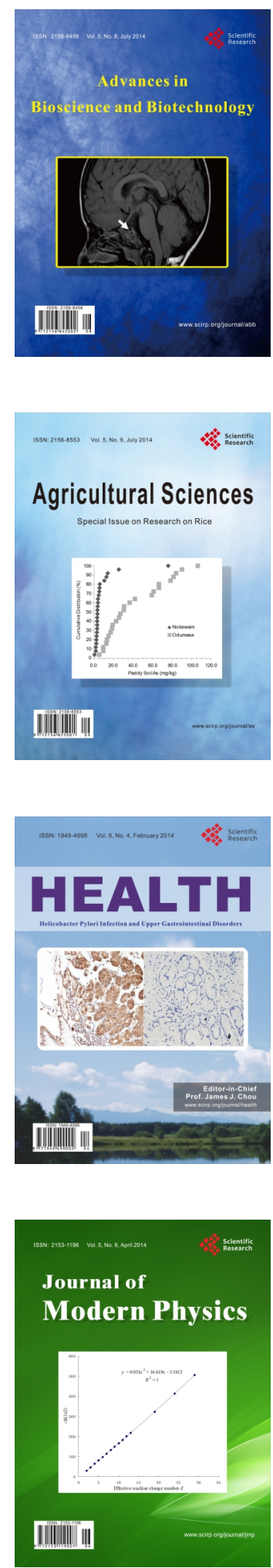
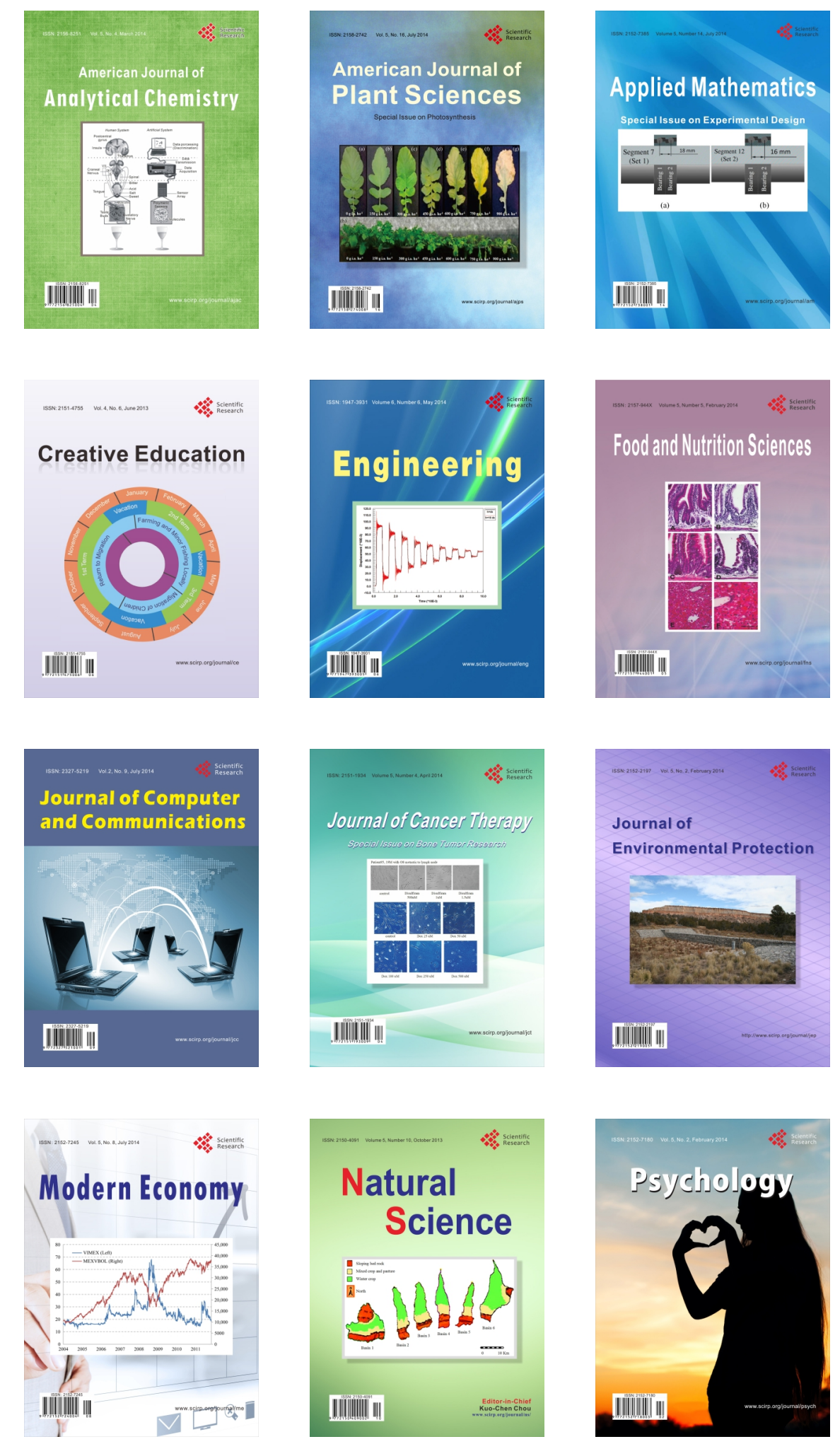